Article

\title{
Alpha-Cyclodextrin Attenuates the Glycemic and Insulinemic Impact of White Bread in Healthy Male Volunteers
}

\author{
Albert Bär ${ }^{1, * D}$, Ioannis Diamantis ${ }^{2}$ and Werner P. Venetz ${ }^{3}$ \\ 1 Bioresco Ltd., 4054 Basel, Switzerland \\ 2 Gastro Center, 2502 Biel, Switzerland; dr.diamantis@hin.ch \\ 3 Datagen AG, 3930 Visp, Switzerland; werner.venetz@datagen.net \\ * Correspondence: contact@bioresco.ch
}

Received: 28 November 2019; Accepted: 3 January 2020; Published: 7 January 2020 updates

\begin{abstract}
The demonstration of a physiological benefit has recently become an indispensible element of the definition of dietary fibers. In the here-reported pilot study, the effect of alpha-cyclodextrin (alpha-CD) on the postprandial glycemic and insulinemic effect of starch was examined. Twelve fasted, healthy male volunteers received, on three subsequent days, a test breakfast consisting of (A) $100 \mathrm{~g}$ fresh white bread (providing $50 \mathrm{~g}$ starch) and $250 \mathrm{~mL}$ drinking water, (B) the same bread with a supplement of $10 \mathrm{~g}$ alpha-CD dissolved in the drinking water, and (C) $25 \mathrm{~g}$ alpha-CD dissolved in drinking water. Capillary and venous blood was sampled before the breakfast and in regular intervals for a three-hour period thereafter. Glucose was determined in capillary blood and insulin in the plasma of venous blood samples. Breakfast (A) led to a rapid rise in blood glucose and insulin. In breakfast (B), alpha-CD reduced the areas under the curve of blood glucose and insulin significantly by $59 \%$ and $57 \%$, respectively, demonstrating that alpha-CD inhibits and thereby delays starch digestion. Treatment (C) was not associated with a rise of blood glucose. Hence, alpha-CD complies with the current definition of dietary fiber in every respect.
\end{abstract}

Keywords: alpha-cyclodextrin; dietary fiber; glycemic response; insulinemic response; amylase; digestion

\section{Introduction}

According to a "Guidance for Industry" that the US Food and Drug Administration (FDA) published in June 2018, isolated or synthetic non-digestible carbohydrates that are added to formulated foods may be declared in nutritional labelling as dietary fiber only if their use has a demonstrated beneficial physiological effect [1]. Attenuation of post-prandial blood glucose and/or insulin levels is a generally recognized beneficial health effect. It may be measured by assessing blood glucose and insulin levels for up to at least two hours after consumption of a standardized meal. However, only studies in which an isolated or synthetic non-digestible carbohydrate is added to a food (rather than substitutes for a food component) provide evidence of an independent, i.e., active glycemia-lowering effect [2].

Alpha-cyclodextrin (CAS 10016-20-3) was shown to be a dietary fiber in compliance with these requirements in a randomized, double-blind crossover study in which ten healthy subjects consumed boiled white rice (containing $50 \mathrm{~g}$ digestible starch) combined with 0 (control), 5, or $10 \mathrm{~g}$ alpha-cyclodextrin (alpha-CD). Measurement of plasma glucose in regular intervals over a two-hour postprandial period showed that the area under the curve (AUC) was negatively related to the alpha-CD dose and that the difference to the untreated controls was significant $(p<0.05)$ for the midand high-dose alpha-cyclodextrin treatment [3]. In the here-reported pilot study, the hypothesis was 
tested that alpha-cyclodextrin lowers the glycemic and insulinemic response to starch ingested with white bread that has a similar high glycemic index to boiled white rice [4] and that therefore is suitable for detecting glycemia and the insulinemia modulating effects of dietary fibers $[5,6]$

\section{Materials and Methods}

\subsection{Recruitment and Ethics}

Twelve healthy male volunteers were recruited from the Heraklion University campus. The subjects were 23-24 years old, had a body weight of 69-85 kg (mean $74.2 \mathrm{~kg}$ ), and appeared to be healthy on medical pre-study screening. None of them consumed a special diet, had a history of gastrointestinal or metabolic disease, or was a smoker. The here-reported study was conducted in accordance with the Declaration of Helsinki. Its protocol and execution were approved and signed by the Ethics Committee of the University Hospital Medical School, Heraklion Greece, P.O. Box 1393, GR-71409 Heraklion, Greece.

After having been informed by the study director (I.D.) about the purpose, procedures, risks, and benefits of the planned study, all participants signed an informed consent document. Monetary compensation was accorded to each participant after partial or full completion of the study.

\subsection{Preparation of Test Meals}

\subsubsection{Bread Preparation}

Bread was prepared fresh every day in the early morning by the kitchen of the University Hospital of Heraklion, Greece. For obtaining $1 \mathrm{~kg}$ bread, ready for consumption, $500 \mathrm{~g}$ white strong flour, $35 \mathrm{~g}$ salt, and $7 \mathrm{~g}$ yeast were mixed in a large bowl. Ten milliliters of olive oil and $300-400 \mathrm{~mL}$ water were added and mixed well. The mixture was kneaded for about $10 \mathrm{~min}$. Once the dough was satin-smooth, it was placed in a lightly oiled bowl and covered with cling film. It was set to rise for 1 hour during, which approximately doubled its volume. The dough was then formed in a ball and placed on a baking parchment. After another hour of rest, it was baked for $25-30 \mathrm{~min}$ in a preheated oven at $200^{\circ} \mathrm{C}$. Between the end of the baking process and the consumption of the bread, there was a resting period of about $3 \mathrm{~h}$.

\subsubsection{Test Product}

The safety of alpha-cyclodextrin as a food additive and later as a food ingredient was assessed by the Joint Food and Agriculture Organization/World Health Organization FAO/WHO Expert Committee on Food Additives (JECFA) in June 2001 and June 2004. An Acceptable Daily Intake (ADI) "not specified" was allocated for both uses [7,8].

For the present study, food-grade alpha-cyclodextrin (Batch No 6P172) was obtained from Wacker Chemie, Munich, Germany. According to this manufacturer's analytical data sheet, this batch had an alpha-cyclodextrin content of $99.1 \%$ on dry basis. The water content was $8.3 \%$ on as is basis (Karl Fischer method).

\subsection{Study Design}

The study was designed as single-blind study, i.e., the participants were unaware of the composition of the two test meals (aqueous solutions of alpha-cyclodextrin are tasteless) and the fact that a sequential treatment plan was applied. The protocol for measuring and calculating the blood glucose response was in line with the procedures recommended by the Food and Agriculture Organization/World Health Organization [6].

On three separate days, each participant received in the morning as breakfast, sequentially, (A) $50 \mathrm{~g}$ starch in the form of $100 \mathrm{~g}$ fresh white bread prepared daily as described in Section 2.2.1, together with $250 \mathrm{~mL}$ plain drinking water from the local water supply; (B) $50 \mathrm{~g}$ starch (100 $\mathrm{g}$ fresh 
white bread) together with $10 \mathrm{~g}$ alpha-cyclodextrin dissolved in $250 \mathrm{~mL}$ drinking water; and (C) $25 \mathrm{~g}$ alpha-cyclodextrin dissolved in $250 \mathrm{~mL}$ drinking water (no bread). The volunteers were instructed to consume the test meals at a comfortable pace within $15 \mathrm{~min}$. Between treatment days there was a "wash-out" period of at least two days. During the 3-h period following the intake of the test meals, the participants remained seated at a table. The consumption of additional water was allowed, but it was recommended not to drink more than $300 \mathrm{~mL}$.

\subsection{Blood Sampling and Analytical Methods}

After overnight fasting for at least ten hours, the subjects arrived between 8.00 and 8.30 a.m. at the clinic. A catheter was placed in the forearm vein for collection of venous blood. Capillary blood was collected from the fingertip in fluorocitrate tubes. Both venous and capillary blood samples were collected just before the consumption of the test meal $(t=0)$ and at $15,30,45,60,75,90,120,150$, and $180 \mathrm{~min}$ thereafter. Capillary whole blood was used for the glucose determinations, because the rise in blood glucose is said to be greater in capillary blood than in venous blood and because the results are less variable $[4,5]$. Glucose was measured in capillary blood using an automated hexokinase method (Olympus No. OSR 6121).

Plasma was prepared from the venous blood samples and stored at $<-18^{\circ} \mathrm{C}$ for about three weeks until insulin was determined in all samples at the same time using an automated radioimmunoassay (DRG Diagnostics Cat. No. EIA 2935). These analyses were performed by AlterChem, Agios Lavras Street 75a, GR-13231 Petroupoli, Greece. The results are expressed in $\mu \mathrm{IU} / \mathrm{mL}(4 \mathrm{ng} / \mathrm{mL}=100 \mu \mathrm{IU} / \mathrm{mL})$.

\subsection{Statistical Analyses}

The incremental area under the curve (iAUC) of each subject's blood glucose and insulin response was calculated according to the trapezoidal rule with baseline value $(t=0)$ as lowest level [6]. Results are given, as appropriate, as mean values \pm standard deviation (SD) or mean values \pm standard error of mean (SEM). Comparison of the treatment groups A and B was performed by repeated-measures analysis of variance (ANOVA) and paired $t$-test with a significance level of $p<0.05$ for treatment $B$ vs. treatment $A$. The spline function of $R$ was used to calculate the interpolation of glucose and insulin values. Statistical analyses were performed using $\mathrm{R}$ version 3.6.0: a language and environment for statistical computing. (R Core Team, 2019), R Foundation for Statistical Computing, Vienna, Austria, without additional library packages.

\section{Results}

\subsection{Participants and Compliance}

The twelve volunteers who entered the study completed it according to protocol. Compliance with the requirement of overnight fasting prior to test days was good, as evidenced by the low basal blood glucose and insulin levels at the start of each treatment (Table 1). There were no significant within-person differences of baseline values.

Table 1. Calculated mean blood glucose and insulin and insulin concentrations of all subjects at the start. $(t=0 \mathrm{~min})$ of each treatment period.

\begin{tabular}{cccccccc}
\hline Treatment & $\mathbf{N}$ & \multicolumn{3}{c}{ Glucose $(\mathbf{m m o l} / \mathrm{L})$} & \multicolumn{2}{c}{ Insulin $(\mu \mathrm{IU} / \mathrm{mL})$} \\
\hline & & Mean & \multicolumn{2}{c}{$\mathbf{9 5 \%}$ CI } & Mean & \multicolumn{2}{c}{$\mathbf{9 5 \%}$ CI } \\
\hline & & \multicolumn{2}{c}{ Lower } & Upper & & Lower & Upper \\
\hline A & 12 & 5.33 & 5.09 & 5.57 & 10.3 & 6.5 & 13.0 \\
B & 12 & 4.97 & 4.62 & 5.33 & 11.6 & 7.6 & 15.6 \\
C & 12 & 4.99 & 4.60 & 5.38 & 13.1 & 8.6 & 17.7 \\
\hline
\end{tabular}

Treatment A: $50 \mathrm{~g}$ starch (as $100 \mathrm{~g}$ fresh white bread) together with $250 \mathrm{~mL}$ drinking water. Treatment B: $50 \mathrm{~g}$ starch (as $100 \mathrm{~g}$ fresh white bread) together with $10 \mathrm{~g}$ alpha-cyclodextrin dissolved in $250 \mathrm{~mL}$ drinking water. Treatment C: $25 \mathrm{~g}$ alpha-cyclodextrin dissolved in $250 \mathrm{~mL}$ drinking water. Abbreviations: CI, Confidence Interval. 


\subsection{Postprandial Glucose and Insulin Response}

The ingestion of about $50 \mathrm{~g}$ starch in the form of $100 \mathrm{~g}$ fresh white bread (treatment A) resulted in the expected rapid rise in capillary blood glucose concentrations reaching the highest level of $8.73 \pm 0.60 \mathrm{mmol} / \mathrm{L}$ after $53.8 \pm 7.7 \mathrm{~min}$. At the end of the postprandial 3-h observation period, the blood glucose concentrations returned to baseline values. Drops below starting levels (rebound effect) were small and were observed in 8 out of 12 subjects between 120 and 180 min after intake of the test meal.

When the fresh white bread was consumed together with $10 \mathrm{~g}$ alpha-cyclodextrin (treatment B), a markedly reduced and delayed glycemic response was observed, with a calculated maximum capillary blood glucose concentration of $6.19 \pm 0.36 \mathrm{mmol} / \mathrm{mL}$ reached at $73.8 \pm 19.7 \mathrm{~min}$ after consumption of the test meal.

The consumption of $25 \mathrm{~g}$ alpha-cyclodextrin with the drinking water (treatment $\mathrm{C}$ ) was associated with an only small increase of blood glucose levels at $60 \mathrm{~min}$ after the test meal. At all other time points, blood glucose levels were not different from the baseline value, i.e., alpha-cyclodextrin did not induce a relevant glycemic response.

The time course of the calculated mean blood glucose values for the three treatments is depicted in Figure 1. The time courses of each individual's blood glucose on each treatment are shown in the Figures S1-S3.

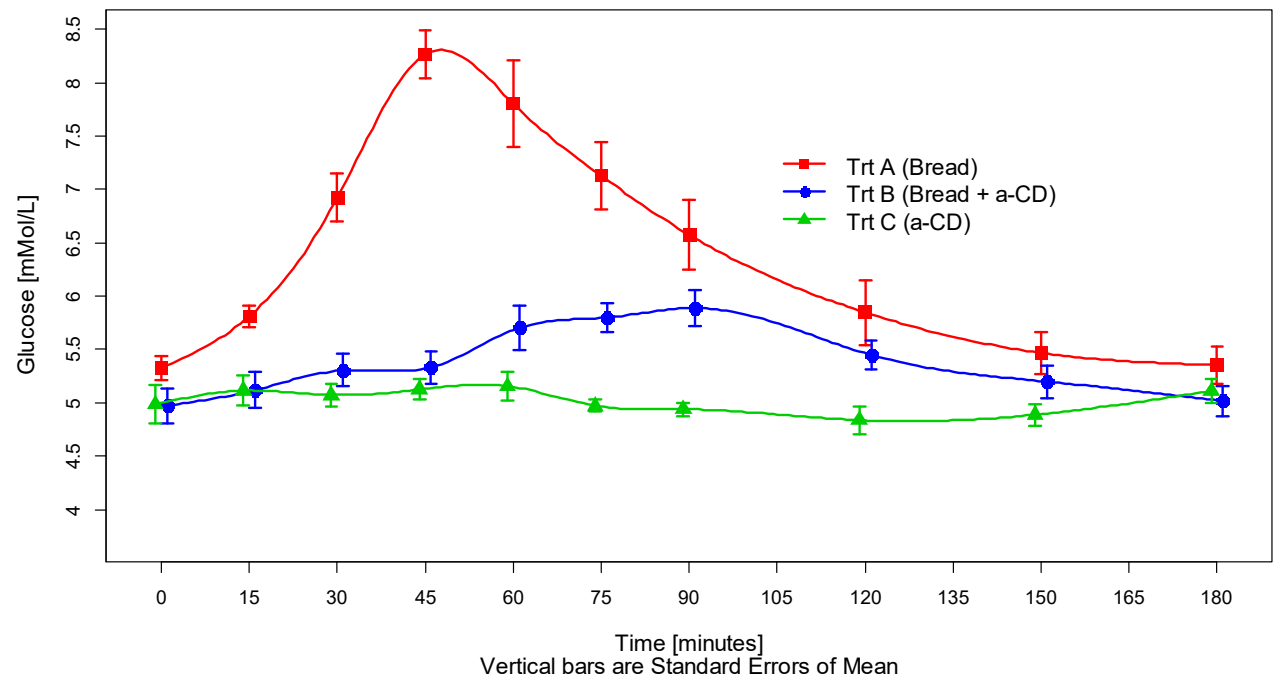

Figure 1. Glycemic response curves elicited by $100 \mathrm{~g}$ white bread consumed with $250 \mathrm{~mL}$ plain drinking water (treatment A), or $100 \mathrm{~g}$ white bread consumed with $250 \mathrm{~mL}$ water containing $10 \mathrm{~g}$ dissolved alpha-cyclodextrin (treatment B) or $250 \mathrm{~mL}$ water with $25 \mathrm{~g}$ dissolved alpha-cyclodextrin (alpha-CD) only (treatment C). Values are the means of the 12 subjects with their SEMs represented by vertical bars. Abbreviations: Trt, treatment; a-CD, alpha-cyclodextrin.

The calculated mean plasma insulin levels rose after consumption of white bread (Treatment A) in the expected way (Figure 2). The addition of alpha-cyclodextrin to white bread (Treatment B) lead to a significantly lower insulin release, which, moreover, occurred with some delay. The intake of $25 \mathrm{~g}$ alpha-cyclodextrin on its own (Treatment C) had no effect on plasma insulin levels. Maximum blood insulin levels were reached with a median of about 45 min after consumption of white bread (treatment A), but with a median of about 75 min after consumption of white bread with alpha-cyclodextrin (treatment B).

Both the glycemic and insulinemic index of the applied white bread consumed together with $10 \mathrm{~g}$ alpha-cyclodextrin in the drinking water was, on average, about $43 \%$ relative to that of the white bread consumed with plain drinking water (Figure 3). The time courses of each participant's blood insulin on each treatment are shown in the Figures S1 and S2. 


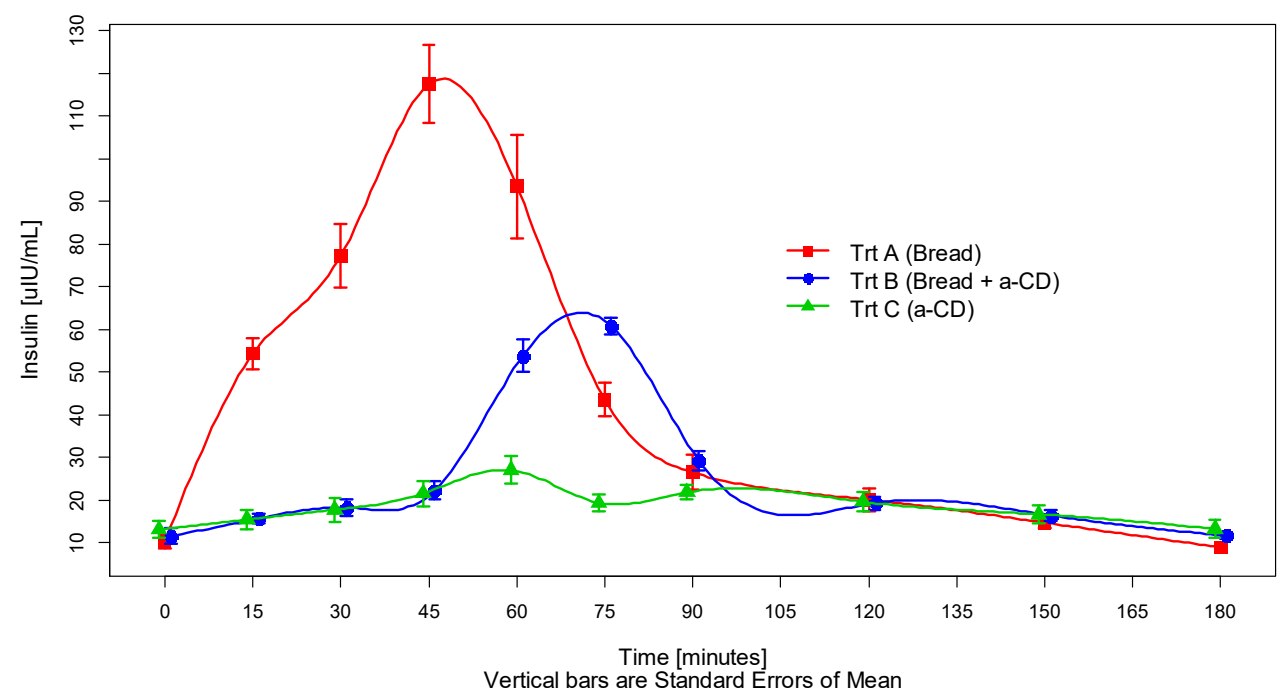

Figure 2. Insulinemic response curves elicited by $100 \mathrm{~g}$ white bread consumed with either $250 \mathrm{~mL}$ plain drinking water (treatment $\mathrm{A}$ ), or $250 \mathrm{~mL}$ drinking water containing $10 \mathrm{~g}$ dissolved alpha-cyclodextrin (treatment B), or $250 \mathrm{~mL}$ drinking water containing $25 \mathrm{~g}$ dissolved alpha-CD only (treatment $\mathrm{C}$ ). Values are the means of 12 subjects with their SEMs represented by vertical bars.

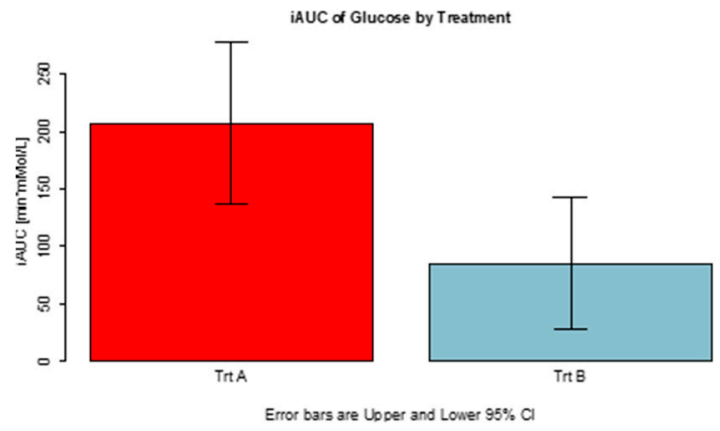

(a)

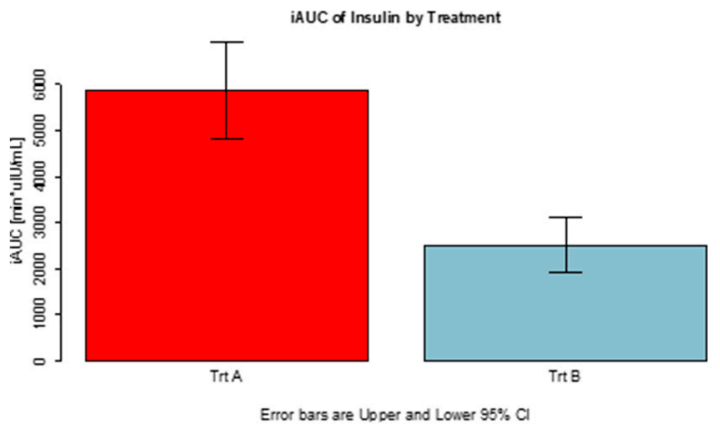

(b)

Figure 3. Integrated areas under curve (iAUC) of the blood glucose and insulin concentrations elicited over a period of 180 minutes by $100 \mathrm{~g}$ white bread consumed with either $250 \mathrm{~mL}$ plain drinking water (treatment A) or $100 \mathrm{~g}$ white bread consumed with $250 \mathrm{~mL}$ drinking water containing $10 \mathrm{~g}$ dissolved alpha-cyclodextrin (treatment B). Values are the means for 12 subjects with their SEMs represented by vertical bars. (a) integretated area under curve of blood glucose by treatment, (b) integrated area under curve of blood insulin by treatment.

\subsection{Side-Effects}

Adverse side-effects were not reported during the periods of bread consumption with or without alpha-cyclodextrin. However, three subjects reported mild bloating and one subject mild diarrhea after completion of treatment $\mathrm{C}$. None of the subjects complained, however, about flatulence or intestinal cramps.

\section{Discussion}

The results of this study demonstrate that the consumption of $10 \mathrm{~g}$ of alpha-cyclodextrin together with fresh white bread, providing $50 \mathrm{~g}$ starch, reduces the post-prandial glycemic and insulinemic response significantly in healthy subjects. This is a beneficial health effect because post-prandial glycemia is related to body fat deposition and the risk of developing certain chronic diseases $[9,10]$ while, vice versa, a low-glycemic diet is favorable for vascular health [11]. 
In several in vitro studies it has been shown that alpha-cyclodextrin inhibits the hydrolysis of amylose by porcine pancreatic alpha-amylase, presumably due to the competitive binding of alpha-cyclodextrin to the enzyme's active site [12-16]. The results of the present study can be explained by this mechanism. However, it may be modulated by other components of more complex foods, such as fat that retards gastric emptying and that, by inhibiting the release of insulin after a meal, may blunt the blood glucose lowering effect of alpha-cyclodextrin [17-19].

Additionally, consistent with the concept of a specific amylase-inhibitory effect of alpha-cyclodextrin, rather than an unspecific effect (e.g., on gastric emptying time) is the observation that alpha-cyclodextrin, given at a dose of $10 \mathrm{~g}$, did not reduce the glycemic response to sucrose $(100 \mathrm{~g}$ single dose ingested with water) in healthy adults [20].

In comparison with other dietary fibers that have been examined for their glycemia lowering effect when added to bread, alpha-cyclodextrin appears to be particularly efficient [21]. Moreover, and in contrast to some other dietary fibers, the incorporation of alpha-CD in foods and beverages does not pose any particular food-technological or gustatory challenges (e.g., taste, viscosity).

Taking the published results into account, the European Food Safety Authority (EFSA) already earlier expressed a favorable opinion on the blood-glucose-lowering health effect of alpha-CD when consumed with a starch-containing meal [22].

\section{Conclusions}

This study demonstrates that the incorporation of alpha-cyclodextrin in a starch-based meal can significantly reduce its postprandial glycemic and insulinemic impact. Further studies are needed to evaluate the health benefits that may result from the regular consumption of foods containing alpha-cyclodextrin over longer periods of time, especially in populations at risk for developing diabetes and cardiovascular disease.

Supplementary Materials: The following are available online at http:/www.mdpi.com/2304-8158/9/1/62/s1. Figure S1: Individual blood glucose levels ( $\mathrm{mmol} / \mathrm{L})$ versus time $(\mathrm{min})$ after consumption of white bread (red lines) and bread with alpha-CD (blue lines), respectively; Figure S2: Individual blood insulin levels $(\mu \mathrm{IU} / \mathrm{mL})$ versus time ( $\mathrm{min})$, after consumption of bread (Treatment $A$ ) and bread with alpha-CD (Treatment B), respectively. Figure S3: Time course of individual blood glucose $(\mathrm{mmol} / \mathrm{L})$ and blood insulin levels $(\mu \mathrm{IU} / \mathrm{mL})$ sorted by subject number (1-12) and treatment (A: white bread, B: white bread and cyclodextrin, C: alpha-cyclodextrin only).

Author Contributions: Conceptualization, A.B. and I.D.; methodology, A.B. and I.D.; software, W.P.V.; validation, A.B., I.D. and W.P.V.; formal analysis, W.P.V.; investigation, A.B. and I.D.; resources, A.B.; I.D. and W.P.V. data curation, I.D. and W.P.V.; writing-original draft preparation, A.B.; writing-review and editing, A.B., I.D. and W.P.V.; visualization, W.P.V.; supervision, A.B.; project administration, A.B. and I.D.; funding acquisition, A.B. All authors have read and agreed to the published version of the manuscript.

Funding: This research was funded by Wacker Chemie AG, Hanns-Seidel-Platz 4, 81737 München, Germany. The funder had no role in the design, execution, data analysis, and reporting of the data.

Conflicts of Interest: The authors declare no conflict of interest.

\section{References}

1. US Food and Drug Administration. The Declaration of Certain Isolated or Synthetic Non-Digestible Carbohydrates as Dietary Fiber on Nutrition and Supplement Facts Labels: Guidance for Industry. June 2018; p. 9. Available online: https://www.fda.gov/regulatory-information/search-fda-guidance-documents/ guidance-industry-declaration-certain-isolated-or-synthetic-non-digestible-carbohydrates-dietary (accessed on 28 November 2019).

2. US Food and Drug Administration. Scientific Evaluation of the Evidence on the Beneficial Physiological Effects of Isolated or Synthetic Non-Digestible Carbohydrates Submitted as a Citizen Petition (21 CFR 10.30): Guidance for Industry. February 2018; p. $19 . \quad$ Available online: https://www.fda.gov/regulatory-information/search-fda-guidance-documents/guidance-industryscientific-evaluation-evidence-beneficial-physiological-effects-isolated-or (accessed on 28 November 2019). 
3. Buckley, J.D.; Thorp, A.A.; Murphy, K.J.; Howe, P.R.C. Dose-dependent inhibition of the post-prandial glycaemic response to a standard carbohydrate meal following incorporation of alpha-cyclodextrin. Ann. Nutr. Metab. 2006, 50, 108-114. [CrossRef] [PubMed]

4. Atkinson, F.S.; Foster-Powell, K.; Brand-Miller, J.C. International tables of glycemic index and glycemic load values: 2008. Diabetes Care 2008, 31, 2281-2283. [CrossRef] [PubMed]

5. Wolever, T.M.S.; Bolognesi, C. Source and amount of carbohydrate affect postprandial glucose and insulin in normal subjects. J. Nutr. 1996, 126, 2798-2806. [CrossRef] [PubMed]

6. FAO. Carbohydrates in human nutrition. Chapter 4: The role of the glycemic index in food choice. Report of a Joint FAO/WHO Expert Consultation. FAO Food Nutr. Paper 1998, 66, 25-30.

7. WHO Technical Report Series 909. In Proceedings of the 57th Report of the Joint FAO/WHO Expert Committee on Food Additives, Rome, Italy, 5-14 June 2001; pp. 40-42.

8. WHO Technical Report Series 928. In Proceedings of the 63rd Report of the Joint FAO/WHO Expert Committee on Food Additives, Geneva, Switzerland, 8-17 June 2005; pp. 16-20.

9. Opperman, A.; Venter, C.; Oosthuizen, W.; Thomson, R.; Vorster, H. Meta-analysis of the health effects of using the glycemic index in meal-planning. Br. J. Nutr. 2004, 92, 367-381. [CrossRef] [PubMed]

10. Brand-Miller, J.C.; Holt, S.H.; Pawlak, D.B.; Mc-Millan, J. Glycemic index and obesity. Am. J. Clin. Nutr. 2002, 76, 281-285. [CrossRef]

11. Jovanovski, E.; Zurbau, A.; Vuksan, V. Carbohydrates and endothelial function: Is a low-carbohydrate diet or a low-glycaemic index diet favourable for vascular health? Clin. Nutr. Res. 2015, 4, 69-75. [CrossRef] [PubMed]

12. Koukiekolo, R.; Desseaux, V.; Moreau, Y.; Marchis-Mouren, G.; Santimone, M. Mechanism of porcine pancreatic $\alpha$-amylase. Inhibition of amylose and maltopentaose hydrolysis by $\alpha-, \beta$ - and $\gamma$-cyclodextrins. Eur. J. Biochem. 2001, 268, 841-848. [CrossRef] [PubMed]

13. Desseaux, V.; Koukiekolo, R.; Moreau, Y.; Santimone, M.; Marchis-Mouren, G. Mechanism of porcine pancreatic $\alpha$-amylase: Inhibition of amylose and maltopentaose hydrolysis by various inhibitors. Biol. Bratisl. 2002, 57, 163-170. Available online: http://biologia.savba.sk/section_c/Suppl_11/Desseaux.pdf (accessed on 28 November 2019).

14. Oudjeriouat, N.; Moreau, Y.; Santimone, M.; Svennson, B.; Marchis-Mouren, G.; Desseaux, V. On the mechanism of $\alpha$-amylase. Acarbose and cyclodextrin inhibition of barely amylase isozymes. Eur. J. Biochem. 2003, 270, 3871-3879. [CrossRef] [PubMed]

15. Larson, S.B.; Greenwood, A.; Cascio, D.; Day, J.; McPherson, A. Refined molecular structure of pig pancreatic $\alpha$-amylase at $2.1 \AA$ resolution. J. Mol. Biol. 1994, 235, 1560-1584. [CrossRef] [PubMed]

16. Wang, M.; Jin, Z.; Liu, L.; Wang, Z.; Li, F.; Sun, W.; Cai, H.; Chen, X.; Shen, W.; Zhu, Z.; et al. Inhibition of cyclodextrins on the activity of $\alpha$-amylase. J. Incl. Phenom. Macrocycl. Chem. 2018, 90, 351-356. [CrossRef]

17. Fletcher, E.N. The effect of alpha-cyclodextrin on acute blood lipid and glycemic responses to a fat containing meal. Wayne State Univ Thesis 2013, 231, 1-29. Available online: https://igitalcommons.wayne.edu/oa_theses (accessed on 28 November 2019).

18. Jarosz, P.A.; Fletcher, E.; Elserafy, E.; Artiss, J.D.; Jen, K.L.C. The effect of $\alpha$-cyclodextrin on postprandial lipid and glycemic responses to a fat-containing meal. Metab. Clin. Exp. 2013, 1443-1447. [CrossRef] [PubMed]

19. Sugahara, M.; Inoue, Y.; Murata, I.; Nakata, D.; Terao, K.; Kanamoto, I. Effect of cyclodextrin on postprandial blood glucose and triglycerides. Int. J. Pharm. 2016, 6, 13-19.

20. Gentilcore, D.; Vanis, L.; Teng, J.C.; Wishart, J.M.; Buckley, J.D.; Rayner, C.K.; Horowitz, M.; Jones, K.L. The oligosaccharide $\alpha$-cyclodextrin has modest effects to slow gastric emptying and modify the glycaemic response to sucrose in healthy older adults. Br. J. Nutr. 2011, 106, 583-587. [CrossRef] [PubMed]

21. Scazzina, F.; Siebenhandl-Ehn, S.; Pellegrini, N. The effect of dietary fibre on reducing the glycaemic index of bread. Br. J. Nutr. 2013, 109, 1163-1174. [CrossRef] [PubMed]

22. EFSA. Scientific Opinion on the substantiation of health claims related to alpha-cyclodextrin and reduction of post-prandial glycaemic responses (ID 2926, further assessment) pursuant to Article 13(1) of Regulation (EC) No 1924/2006. EFSA J. 2012, 10, 2713.

(C) 2020 by the authors. Licensee MDPI, Basel, Switzerland. This article is an open access article distributed under the terms and conditions of the Creative Commons Attribution (CC BY) license (http://creativecommons.org/licenses/by/4.0/). 